OPEN ACCESS

Edited by:

Llewellyn Ellardus Van Zyl,

Eindhoven University of Technology,

Netherlands

Reviewed by:

Leoni Van Der Vaart,

North-West University, South Africa

Wei $X u$,

Nanjing Normal University, China

${ }^{*}$ Correspondence:

Xiaomin Sun

sunxiaomin@bnu.edu.cn

Specialty section:

This article was submitted to

Organizational Psychology,

a section of the journal

Frontiers in Psychology

Received: 30 April 2019

Accepted: 19 August 2019

Published: 28 August 2019

Citation:

Zhu Y, Sun X, Liu S and Xue G

(2019) Is Greed a Double-Edged

Sword? The Roles of the Need

for Social Status and Perceived

Distributive Justice in the Relationship

Between Greed and Job

Performance.

Front. Psychol. 10:2021

doi: 10.3389/fpsyg.2019.02021

\section{Is Greed a Double-Edged Sword? The Roles of the Need for Social Status and Perceived Distributive Justice in the Relationship Between Greed and Job Performance}

\author{
Yiming Zhu' ${ }^{1}$ Xiaomin Sun ${ }^{*}$, Sijia Liu ${ }^{1}$ and Gang Xue ${ }^{2}$ \\ ${ }^{1}$ Beijing Key Laboratory of Applied Experimental Psychology, National Demonstration Center for Experimental Psychology \\ Education (Beijing Normal University), Faculty of Psychology, Beijing Normal University, Beijing, China, ${ }^{2}$ Department of Public \\ Administration, Chinese Academy of Governance, Beijing, China
}

Greed is one of the most common features of human nature, and it has recently attracted increasing research interest. The aims of this paper are to provide one of the first empirical investigations of the effects of greed on job performance and to explore the mediating role of the need for social status and perceived distributive justice. Using a working sample $(N=315)$ from China, the current study found that greed promoted both task and contextual performance through the intermediary effect of the need for social status. At the same time, greed inhibited both types of performance through perceived distributive justice. These results confirmed our hypothesis that greed is a double-edged sword with opposite effects on one's performance. The findings suggest that organizations should both address greedy employees' social status concerns and ensure that they are treated fairly so that organizations can fully utilize the talents of greedy people and channel their energy in a beneficial direction.

\footnotetext{
Keywords: greed, perceived distributive justice, need for social status, task performance, contextual performance
}

\section{INTRODUCTION}

The discussion on greed is as old as the discussion on wealth and power. Although a consensus has been reached that greed is a common and inevitable part of human nature (Balot, 2001; Wang et al., 2011), people seem to hold different attitudes toward greed. The famous quote by the lead character in the movie Wall Street says, "greed. . . captures the essence of the evolutionary spirit. Greed. . .has marked the upward surge of mankind." In fact, greed is highly valued in some organizations and societies (Bruhn and Lowrey, 2012). In contrast, almost all religions treat greed as immoral and evil (Wang et al., 2011). Similarly, studies have suggested that greed is associated with many negative characteristics (Gilliland and Anderson, 2011). It makes people focus only on their personal fulfillment and satisfaction, ignoring norms and values (Levine, 2005), and this focus may explain why greed is associated with such negative behaviors as fraud (Smith, 2003), deception (Cohen et al., 2009), theft (Caudill, 1988), corruption (Rose-Ackerman, 1999), and other unethical behaviors (Seuntjens et al., 2019). 
Many economists tend to believe that greed is good, claiming that greed is the driving force of economic development (Greenfeld, 2003). The argument is that if people are eager to maximize their own interests and are never satisfied with their current possessions, they will eventually engage in activities that are beneficial to the whole society (Oka and Kuijt, 2014). The underlying logic of this proposition is that greed promotes individual performance, which in turn benefits the development of organizations and societies. However, there is a missing link regarding whether greed facilitates individual performance.

The relationship between greed and performance is far from self-evident. In organizational settings, where individuals work together with others and social status is valued even more highly than money (Ezard, 2000). Thus, employees with higher level of greed are more likely to have a higher level of the need for social status, which makes them work harder to gain the status they long for. Meanwhile, greed may distort people's perception of distributive justice, which may in turn hold them back from devoting themselves to their work. In sum, it seems two different paths may exist through which greed could affect performance. In the current study, we tested the facilitating effect of greed on performance through the need for social status and the inhibiting effect of greed on performance through perceived distributive justice.

Greed is an inherent part of human nature, and performance prediction is of great importance for organizational research and practice. Organizational psychologists Bruhn and Lowrey (2012) claimed that greed could simultaneously have both positive and negative impacts on organizational and individual performance, but until now, few empirical studies have tested whether and how greed promotes or diminishes employees' performance. The current study aimed to depict the nuanced relation and inner mechanisms between greed and performance. The results are helpful for researchers and practitioners to reflect under what conditions could greed improve or decrease performance, which is crucial from both academic and practical viewpoints.

\section{Greed and Job Performance}

Although we use the concept of greed often in everyday life, there is a lack of a consistent definition of greed (Wang et al., 2011). Some definitions emphasize the "cost to others," which indicates that greed is socially harmful (Balot, 2001; Mussel et al., 2015). For example, (Veselka et al., 2014, p. 76) defined greed as "the tendency to manipulate and betray others for personal gain." Contrary to the assertion of Balot (2001), Veselka et al. (2014), and Seuntjens et al. (2015) suggested that greed does not necessarily lead to a "cost to others." They performed a series of prototype analyses to explore lay conceptualizations of greed and found two central elements of greed: "always wanting more" and "never being satisfied" (Seuntjens et al., 2015). As a result, they constructed a working definition of greed as "the experience of desiring to acquire more and the dissatisfaction of never having enough" (Seuntjens et al., 2015, p. 518) and developed the Dispositional Greed Scale to measure greed (Seuntjens et al., 2015). In the present study, we agreed that greed is not intrinsically moral or immoral and thus adopted Seuntjens et al. (2015) definition of greed.
To explore the relationship between greed and performance, we used a two-dimensional performance categorization. Although models of job performance contain many different dimensions, two major categories of job performance can be found across models: task performance and contextual performance (Borman and Motowidlo, 1997). Task performance refers to behaviors that "bear a direct relation to the organization's technical core, either by executing its technical processes or by maintaining and servicing its technical requirements" (Motowidlo and Van Scotter, 1994, p. 476). Contextual performance includes interpersonal behaviors that "support the broader organizational, social, and psychological environment in which the technical core must function" (Motowidlo and Van Scotter, 1994, p. 476). In the following section, we will theoretically develop the complex pathways from greed to these two types of performance and discuss the underlying mechanism that makes both the positive and negative routes possible.

\section{Greed Is Positively Related to Performance: The Mediating Role of the Need for Social Status}

Social status is the degree to which an individual or group is respected by others (Magee and Galinsky, 2008). The need for social status arises from the social system in which we live (Brown et al., 2011) because higher social status enables individuals to obtain more resources and social benefits. Based on a comprehensive review of diverse empirical literature, Anderson et al. (2015) suggested that the need for social status is a fundamental human motive. Seuntjens et al. (2015) prototype analysis suggested that greed involves not only a desire for material goods but also non-material desires, such as for power and status. Moreover, since the main characteristic of greed is to maximize one's own interests (Seuntjens et al., 2015), and since improving one's social status is an effective way to acquire what he or she wants, it is reasonable to argue that people with higher levels of greed may have stronger desires for social status. Research on materialism has also provided indirect evidence that materialism is positively related to statusseeking (Flynn et al., 2016). Materialism refers to the importance that individuals attach to worldly possessions (Belk, 1985) and is found to be closely related to greed (Seuntjens et al., 2015) because both constructs emphasize materialistic desires, while greed also includes non-materialistic objects.

The need for social status has a great impact on one's performance. Individuals generally value higher social status, and group members tend to accord status to employees who are perceived to be highly contributive (Kilduff et al., 2016). Thus, people with a higher need for social status are more likely to work hard to earn others' respect and obtain a higher status. The extant literature provides evidence supporting the positive association between the need for social status and job performance. Specifically, for task performance, researchers have suggested that people pursue status by showing their ability to promote group outcomes (Anderson and Kilduff, 2009) or their commitment to group success (Willer, 2009). For contextual performance, researchers have found that status-seeking members are more 
likely to help others (Flynn et al., 2006) and even sacrifice their own interest to do so (Hardy and Van Vugt, 2006).

Combining the preceding arguments, we propose a critical mediating role of the need for social status, such that greed could facilitate job performance by stimulating employees' propensity to seek social status.

Hypothesis 1a: The need for social status plays a positive mediating role in the relation between greed and task performance.

Hypothesis 1b: The need for social status plays a positive mediating role in the relation between greed and contextual performance.

\section{Greed Is Negatively Related to Performance: The Mediating Role of Perceived Distributive Justice}

Distributive justice addresses whether tangible or intangible rewards and benefits are distributed to employees fairly (Leventhal, 1976). Although justice depends mainly on the regulation and practice of organizations, researchers have suggested that individuals' perceptions of fairness and their reactions to unfair outcomes might differ due to individual differences in equity sensitivity (Kickul and Lester, 2001).

According to research on equity sensitivity, benevolent individuals accept a reduced allocation and perceive less injustice (Kickul and Lester, 2001). In contrast, people with higher psychological entitlement, which is a sense that one deserves more and is entitled to more than others (Campbell et al., 2004), are more likely to feel that the outcome is unfair (Huseman et al., 1987; Kickul and Lester, 2001). Since "getting more" is emphasized in the concept of psychological entitlement and earlier research has shown that greed is highly correlated with psychological entitlement (Liu et al., 2019), it is reasonable to speculate that greed may share the same feature. Greedy people always want more and are never satisfied. As a result, they tend to believe that what they have been allocated is less than what they deserve, which could then generate a sense of distributive injustice.

The perception of distributive injustice is detrimental to employees' performance. According to justice theory (Adams, 1965), if employees feel that their organization is fair and they receive enough rewards from their work, they are more likely to work diligently. In contrast, if employees perceive injustice, one possible way for them to restore justice is to decrease their work performance accordingly. Perceptions of unfairness may deliver a risk signal to employees that their organization does not respect their contribution (Greenberg, 2004), and employees might be inclined to protect their own interests, which could lead to poorer performance (Alesina et al., 2004).

Previous studies have confirmed the impact of perceived justice on task performance and contextual performance. For example, researchers have shown that perceived distributive justice is positively related to job performance (Colquitt et al., 2001) and is negatively related to many counterproductive work behaviors, such as theft (Greenberg, 2002), workplace revenge
(Tripp et al., 2002), and sabotage (Ambrose et al., 2002). A metaanalysis showed that employees' organizational citizenship behaviors, a construct closely related to contextual performance, depend largely on their perceptions of distributive justice and procedural justice (Colquitt et al., 2013).

Based on the preceding arguments, we propose a critical mediating role of perceived distributive justice, through which greed reduces employees' job performance.

Hypothesis 2a: Perceived distributive justice plays a negative mediating role in the relation between greed and task performance.

Hypothesis 2b: Perceived distributive justice plays a negative mediating role in the relation between greed and contextual performance.

\section{MATERIALS AND METHODS}

\section{Participants and Procedure}

Online survey questionnaires were administered by the primary researchers responsible for this project. The study was reviewed and approved by the Academic Ethics Committee at the first author's institution before being conducted. All participants completed the survey online. Before the survey began, a brief description of the survey and the participants rights and responsibilities was presented. Knowing that their completion of the survey and their participation was completely voluntary, the participants provided their consent to participate by clicking the "I agree" button. Debriefing information was also provided online at the end of the survey.

Participants were recruited from a paid research participation system $^{1}$, which is used by millions of users in China. Four items in the survey were used as attention checks. The first item was presented soon after the participants provided their consent to participate. The participants were asked whether they were going to answer the questions in the survey seriously. For those who responded by "no," the survey was terminated immediately. For those who checked "yes," this item served as a promise from the participant that was aimed at increasing participants' commitment to complete the survey conscientiously. Another three attention check items were positioned randomly in the survey. A sample item is as follows: "To make sure the screen is working well, please choose the second response option for this item." The correct answer changed for the other two items. These three items were used to detect participants who failed to read items carefully and chose their responses blindly. Participants who failed any one of the items were regarded as unqualified. The criterion for participant screening was entered into the research participation system beforehand. Only those who passed the attention checks remained in the dataset.

Three hundred and fifteen participants comprised the final sample. All participants had jobs and came from various regions in China. Specifically, 137 (43.49\%) participants came from East China, 54 (17.14\%) came from South China, 37 (11.75\%) came

\footnotetext{
${ }^{1}$ www.sojump.com
} 
from North China, 31 (9.84\%) came from Central China, 16 (5.08\%) came from Southwest China, 11 (3.49\%) came from Northwest China, and 29 (9.21\%) came from Northeast China. The sample consisted of 130 males (41.3\%). The participants' ages ranged from 21 to 59 years $(M=32.53, S D=6.70)$, and the participants' organizational tenure ranged from 1 to 40 years $(M=9.15, S D=6.38)$. For the highest educational degree achieved, the majority of the participants $(n=253 ; 80.32 \%)$ had received a university education, 31 (9.84\%) people had received a college education, $21(6.67 \%)$ people had received a master's level or higher education, $8(2.54 \%)$ people had received a high school education, $1(0.32 \%)$ person had received a primary school education and $1(0.32 \%)$ person had received a middle school education. Each participant received 8 Chinese Yuan for their participation. All research data from this study are available at Mendeley Data.

\section{Measures}

Greed was measured by the Chinese version (Liu et al., 2019) of the seven-item Dispositional Greed Scale originally developed by Seuntjens et al. (2015). All items (e.g., "It doesn't matter how much I have. I'm never completely satisfied") were rated using a five-point scale ( 1 = strongly disagree, $5=$ strongly agree), with higher scores representing higher levels of greed. Liu et al. (2019) demonstrated that the psychometric properties of the Chinese version of the Dispositional Greed Scale are satisfactory. In the current study, the Cronbach's alpha of the scale was 0.86 .

The need for social status was measured by the eight-item scale developed by Flynn et al. (2006). All items (e.g., "I want my peers to respect me and hold me in high esteem") were rated using a six-point scale ( 1 = strongly disagree, $6=$ strongly agree), with higher scores representing higher levels of need for social status. In the current study, the scale was translated into Chinese strictly following the back-translation method (Brislin, 1970). The Cronbach's alpha of the scale was 0.83 .

Perceived distributive justice was measured by the Chinese version (Wang, 2009) of the five-item scale originally developed by Niehoff and Moorman (1993). All items (e.g., "I think that my level of pay is fair") were rated using a five-point scale ( 1 = strongly disagree, $5=$ strongly agree), with higher scores representing higher levels of perceived distributive justice. Wang (2009) demonstrated that the psychometric properties of the Chinese version of the scale are satisfactory. In the current study, the Cronbach alpha of the scale was 0.82 .

Employee performance was measured by the Chinese version (Wang and Liao, 2009) of a 17-item scale originally developed by Van Dyne and LePine (1998). The scale includes two dimensions, namely, task performance (four-items; e.g., "I can fulfill the responsibilities specified in my job description") and contextual performance (13-items; e.g., "I have volunteered to do things for my work group"). All items were rated on a five-point scale $(1=$ strongly disagree, $5=$ strongly agree), with higher scores representing higher levels of performance. Wang and Liao (2009) demonstrated that the psychometric properties of the Chinese version of the scale are satisfactory. In the current study, the Cronbach's alphas of the task performance and contextual performance subscales were 0.67 and 0.81 , respectively.
We included gender ( $1=$ male, 2 = female), age (in years), and educational level $(1=$ primary school, 2 = middle school, 3 = high school, $4=$ college, $5=$ university, $6=$ master or higher) in the survey as these biographic variables may influence level of job performance and are commonly controlled in organizational researches (Motowidlo and Van Scotter, 1994; Ambrose et al., 2002; Kilduff et al., 2016). Besides, we also measured organizational tenure (in years), because it may have an impact on employees' perceptions of distributive justice as well as job performance (De Clercq et al., 2018).

\section{Analysis Strategy}

Before testing the hypothesized model, we examined the measurement models first. All variables were modeled as latent factors with their item means as indicators of the latent constructs. Confirmatory factor analyses (CFAs) using maximum likelihood estimation in IBM SPSS AMOS 26 were performed to check the models. Items with loadings less than 0.30 were deleted, and model fit was ascertained using various indices: the composite reliability should be above 0.60 (Fornell and Larcker, 1981), the comparative fit index (CFI) and the Tucker-Lewis index (TLI) should exceed 0.90, the root mean square error of approximation (RMSEA) should be less than 0.08 , and the standardized root mean square residual (SRMR) should be less than 0.05 (Byrne, 2012). Specifically, the latent factor greed was modeled with the seven items as indicators; the latent factor need for social status was modeled with the eight items as indicators; the latent factor perceived distributive justice was modeled with the five items as indicators; the latent factor task performance was modeled with the four items as indicators; and the latent factor contextual performance was modeled with the 13-items as indicators. We next checked whether common method variance existed following Podsakoff et al. (2003) method. Finally, we examined the hypothesized model using latent variable path analyses with structural equation modeling (SEM). The mediating role of perceived distributive justice and need for social status was tested using the bootstrap option (5000 bootstrap samples).

\section{RESULTS}

\section{Descriptive Statistics}

Table 1 presents the means, standard deviations, and correlations among variables. As expected, greed was positively correlated with need for social status $(r=0.30, p<0.01)$ and negatively correlated with perception of distributive justice $(r=-0.16$, $p<0.01$ ). In addition, both need for social status and perception of distributive justice were positively correlated with task performance $(r s>0.31, p s<0.01)$ and contextual performance $(r s>0.45, p s<0.01)$.

\section{Measurement Models}

First, we tested every measurement model of the study variables. For greed, which was modeled with six indicators after deleting an item ("I can't imagine having too many things") because of low loading $(0.29<0.3)$, there was an adequate fit to the data 
TABLE 1 | Descriptive statistics and correlations among the study variables $(N=315)$.

\begin{tabular}{|c|c|c|c|c|c|c|c|c|c|}
\hline & 1 & 2 & 3 & 4 & 5 & 6 & 7 & 8 & 9 \\
\hline \multicolumn{10}{|l|}{ (1) Gender } \\
\hline (2) Education & 0.02 & - & & & & & & & \\
\hline (3) Age & $-0.22^{* *}$ & -0.07 & - & & & & & & \\
\hline (4) OT & $-0.23^{* *}$ & -0.04 & $0.93^{* *}$ & - & & & & & \\
\hline (5) Greed & -0.06 & -0.08 & -0.01 & 0.01 & (0.86) & & & & \\
\hline (6) NFSS & 0.01 & -0.03 & -0.01 & 0.00 & $0.30^{* *}$ & (0.83) & & & \\
\hline (7) DJ & 0.07 & 0.02 & -0.11 & $-0.13^{*}$ & $-0.16^{* *}$ & $0.31^{* *}$ & $(0.82)$ & & \\
\hline (8) TP & 0.06 & 0.10 & $0.13^{*}$ & 0.11 & -0.10 & $0.31^{* *}$ & $0.32^{* *}$ & $(0.67)$ & \\
\hline (9) $\mathrm{CP}$ & $-0.11^{*}$ & 0.06 & 0.05 & 0.03 & 0.00 & $0.45^{* *}$ & $0.45^{* *}$ & $0.44^{* *}$ & $(0.81)$ \\
\hline$M$ & & & 32.53 & 9.15 & 21.35 & 35.83 & 19.28 & 17.49 & 52.98 \\
\hline$S D$ & & & 6.71 & 6.38 & 5.71 & 4.61 & 3.08 & 1.68 & 5.34 \\
\hline
\end{tabular}

*p $<0.05, * * p<0.01$. Participants' gender was dummy coded, with male coded as "1" and female coded as "2." OT, organizational tenure; NFSS, need for social status; DJ, distributive justice; TP, task performance; CP, contextual performance.

$\left(\chi^{2}=33.26, p<0.001, d f=9, \chi^{2} / d f=3.70, \mathrm{CFI}=0.97, \mathrm{TLI}=0.96\right.$, RMSEA $=0.09$, SRMR $=0.03)$. For need for social status, after specifying a correlation between reverse-scored items, item 2 ("I am not concerned with my status among my peers") and item 7 ("I don't care whether others view me with respect and hold me in esteem"), there was an adequate fit to the data $\left(\chi^{2}=86.81\right.$, $p<0.001, d f=19, \chi^{2} / d f=4.57, \mathrm{CFI}=0.91$, TLI $=0.87$, RMSEA $=0.11$, SRMR $=0.07)$. For perceived distributive justice, there was a satisfactory fit to the data $\left(\chi^{2}=18.07, p<0.001\right.$, $d f=5, \chi^{2} / d f=3.61, \mathrm{CFI}=0.98, \mathrm{TLI}=0.95, \mathrm{RMSEA}=0.09$, $\mathrm{SRMR}=0.03)$. For task performance, there was a satisfactory fit to the data $\left(\chi^{2}=1.24, p=0.54, d f=2, \chi^{2} / d f=0.62\right.$, $\mathrm{CFI}=1.00$, TLI $=1.01$, RMSEA $=0.00, \mathrm{SRMR}=0.01)$. For contextual performance, after deleting an item ("I communicate my opinions about work issues to others in my group even if my opinion is different and others in the group disagree with me.") because of low loading $(0.24<0.3)$, there was a satisfactory fit to the data $\left(\chi^{2}=142.83, p<0.001, d f=65, \chi^{2} / d f=2.20, \mathrm{CFI}=0.90\right.$, $\mathrm{TLI}=0.88, \mathrm{RMSEA}=0.07, \mathrm{SRMR}=0.05)$. The factor loadings of all items measuring study variables ranged between 0.40 and 0.75 (Table 2 shows the results).

To ensure that common method variance was not a problem, we tested an alternative model with all factors collapsed into one latent factor (Podsakoff et al., 2003; Akkermans et al., 2018). This model showed a significantly worse fit than the final measurement model $\left(\Delta \chi^{2}=2093.93, \Delta d f=4, p<0.001\right)$. Hence, our hypothesized measurement model showed a better fit to the data.

\section{Structural Model}

We finally tested a hypothesized structural model controlling the effects of demographic variables on task performance and contextual performance. With a correlation between age and organizational tenure, fit indices of the overall hypothesized structural model showed that the model fit the data adequately $\left(\chi^{2}=1198.70, p<0.001, d f=727, \chi^{2} / d f=1.65\right.$, CFI $=0.90$, TLI $=0.89$, RMSEA $=0.05$, SRMR $=0.07$ ).

As Figure 1 suggests, greed had a significantly negative direct effect on task performance $(B=-0.09, \mathrm{SE}=0.03, \beta=-0.22$, $p=0.007)$. The direct effect of greed on contextual performance was non-significant $(B=-0.02, \mathrm{SE}=0.02, \beta=-0.08, p=0.206)$.

Next, greed was positively related to need for social status $(B=0.15, \mathrm{SE}=0.03, \beta=0.36, p<0.001)$, and need for social status was positively related to both task performance $(B=0.43$, $\mathrm{SE}=0.10, \beta=0.41, p<0.001)$ and contextual performance $(B=0.34, \mathrm{SE}=0.07, \beta=0.48, p<0.001)$. In addition, need for social status was a significant mediator of the relations between greed and task performance [standardized indirect effect $=0.06$, $p<0.001,95 \% \mathrm{CI}=(0.03,0.12)]$ and a significant mediator of the relations between greed and contextual performance [standardized indirect effect $=0.05, p<0.001,95 \% \mathrm{CI}=(0.03$, $0.08)]$. The results support both Hypotheses $1 \mathrm{a}$ and $1 \mathrm{~b}$.

Finally, greed was negatively related to perceived distributive justice $(B=-0.09, \mathrm{SE}=0.04, \beta=-0.16, p=0.03)$, and perceived distributive justice was positively related to both task performance $(B=0.21, \mathrm{SE}=0.06, \beta=0.30$, $p=0.005)$ and contextual performance $(B=0.25, \mathrm{SE}=0.04$, $\beta=0.46, p=0.001)$. In addition, perceived distributive justice was a significant mediator of the relations between greed and task performance [standardized indirect effect $=-0.02$, $p=0.02,95 \% \mathrm{CI}=(-0.05,-0.00)]$ and a significant mediator of the relations between greed and contextual performance [standardized indirect effect $=-0.02, p=0.02,95 \% \mathrm{CI}=(-0.05$, $-0.00)]$. The results support both Hypotheses $2 \mathrm{a}$ and $2 \mathrm{~b}$.

\section{DISCUSSION}

Greed has attracted increasing research interest in recent years. Researchers have explored how greed is related to one's personality (e.g., Gilliland and Anderson, 2011), values and beliefs (e.g., Levine, 2005; Liu et al., 2019), and ethical behaviors (e.g., Seuntjens et al., 2019). The current study is one of the first empirical investigations of the dual effects of greed on employees' performance and the underlying mechanisms. The results confirmed the hypotheses that greed has opposite effects on one's performance. Specifically, greed could motivate individuals to work hard but also could diminish their desire to demonstrate 
TABLE 2 | Item loadings for each construct in the best fitting structural model.

\begin{tabular}{|c|c|c|c|}
\hline Variables & Item & Loadings & Composite reliability \\
\hline \multirow[t]{6}{*}{ Greed } & DG1 & 0.75 & 0.89 \\
\hline & DG2 & 0.72 & \\
\hline & DG3 & 0.66 & \\
\hline & DG4 & 0.77 & \\
\hline & DG5 & 0.80 & \\
\hline & DG6 & 0.79 & \\
\hline \multirow[t]{8}{*}{ Need for social status } & NFSS1 & 0.47 & 0.82 \\
\hline & NFSS2 & 0.44 & \\
\hline & NFSS3 & 0.73 & \\
\hline & NFSS4 & 0.75 & \\
\hline & NFSS5 & 0.62 & \\
\hline & NFSS6 & 0.72 & \\
\hline & NFSS7 & 0.48 & \\
\hline & NFSS8 & 0.62 & \\
\hline \multirow[t]{5}{*}{ Perceived distributive justice } & PDJ1 & 0.63 & 0.83 \\
\hline & PDJ2 & 0.75 & \\
\hline & PDJ3 & 0.72 & \\
\hline & PDJ4 & 0.75 & \\
\hline & PDJ5 & 0.64 & \\
\hline \multirow[t]{4}{*}{ Task performance } & TP1 & 0.69 & 0.66 \\
\hline & TP2 & 0.47 & \\
\hline & TP3 & 0.55 & \\
\hline & TP4 & 0.57 & \\
\hline \multirow[t]{12}{*}{ Contextual performance } & CP1 & 0.53 & 0.81 \\
\hline & CP2 & 0.40 & \\
\hline & CP3 & 0.49 & \\
\hline & CP4 & 0.42 & \\
\hline & CP5 & 0.50 & \\
\hline & CP6 & 0.46 & \\
\hline & CP7 & 0.48 & \\
\hline & CP8 & 0.55 & \\
\hline & CP9 & 0.60 & \\
\hline & CP11 & 0.58 & \\
\hline & CP12 & 0.49 & \\
\hline & CP13 & 0.63 & \\
\hline
\end{tabular}

good performance. In addition, we found that greed promoted performance through the intermediary effect of the need for social status but simultaneously inhibited performance through perceived distributive justice. The pattern of the relationship generally held for both task and contextual performance.

The two key elements of greed are "wanting more" and "never being satisfied with what one already has" (Seuntjens et al., 2019). In organizational settings, these features have a very large influence on employees' attitudes toward valuable material resources (such as money) and non-material resources (such as power). The dual effect of greed on people's performance in organizations and the mediating role of need for social status and perceived distributive justice could all be traced back to the key features of greed.

In terms of the "wanting more" aspect of greed, a higher social status is necessary given that resources are generally distributed according to one's standing in the social hierarchy of the organization (Highhouse et al., 2016). The findings of the current study provide some empirical evidence that the greedier an individual is, the stronger his or her need for social status, and the higher his or her level of performance. These results are also consistent with previous research findings that greedy individuals are more productivity-oriented and have a stronger desire to win (Krekels and Pandelaere, 2015). Although some researchers have claimed that greed is socially harmful (Krekels et al., 2011), greedy people's need for higher social status may lead to beneficial behaviors toward both themselves (task performance) and others (contextual performance), which ultimately benefits organizations.

The "dissatisfaction" aspect of greed inevitably influences people's attitudes toward what they have already been allocated. In other words, the dissatisfaction experienced by greedy people casts doubt on the distributive justice of organizations. As a result, the subjective perception of distributive injustice is likely to undermine employees' performance. Although the effect size is small, the findings of the current study provide some empirical evidence that the greedier an individual is, the lower his or her perceived distributive justice and the poorer his or her level of performance. The results of the current study contribute to the literature on equity sensitivity (Huseman et al., 1987) by suggesting that greedy people, similar to those people with higher psychological entitlement, are hypersensitive to distributive justice.

Based on the above findings, greed is likely to be a double-edged sword for employees' job performance in organizations. Differing attitudes toward greed remain in the literature. As mentioned previously, economists tend to affirm greed's positive impacts (Greenfeld, 2003), while most psychological studies have focused on its negative effects (Smith, 2003; Cohen et al., 2009; Seuntjens et al., 2019). Although some researchers have argued the dual effects of greed, they often have developed their propositions from an interpersonal perspective, i.e., that greed could benefit the individual himself or herself but do harm to others (Bruhn and Lowrey, 2012). This idea is consistent with Hume (2001) claim that greed, on the one hand, encourages people to do better and, on the other hand, has devastating consequences for society.

The current study extends the double-edged nature of greed to the intrapersonal domain. We found that even for greedy people themselves, greed could simultaneously facilitate and impede their performance. These findings are important contributions to the field because they suggest that greed is not necessarily good or bad. Its valence depends on what is motivating greedy people. If the desire for social status is stimulated, greedy people could contribute to organizations by improving not only their task performance but also their contextual performance. However, if greedy people are haunted by the perceived distributive injustice of an organization, their performance might be negatively affected. For organizations, the conditions under which greed could generate beneficial outcomes is a more meaningful question than whether greed is good or bad or should be encouraged or curbed. The important practical implication of 


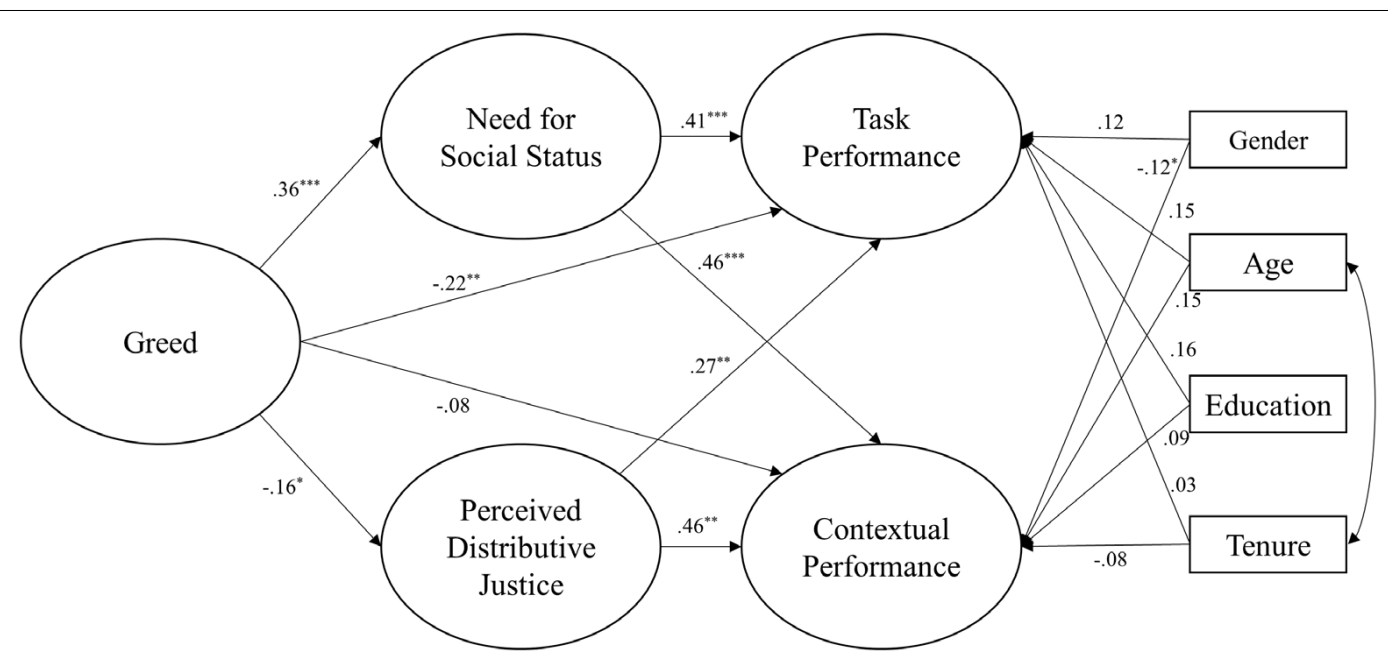

FIGURE 1 | Results of the empirical model test. ${ }^{*} p<0.05,{ }^{* *} p<0.01,{ }^{* * *} p<0.001$.

the current study is that organizations should both address greedy employees' social status concerns and ensure that they are treated fairly so that they can fully utilize the talents of greedy people and channel their energy in a more constructive direction.

\section{Limitations and Future Directions}

First, given that the current study employed a cross-sectional design, further longitudinal study is needed before any causal relationships can be established. For example, the current study proposed that greed is a determinant of the need for social status. However, it is also possible that the need for social status might make people greedy. A cross-lagged panel design would help researchers to confirm the causality relations in our model.

Second, the current study used self-rating scales to measure employees' task and contextual performance as well as other constructs, so common method variance may be an issue. However, following Podsakoff et al.'s (2003) method, we found that common method variance was not a serious problem in the current study. Meanwhile, researchers have found that self-rated performance is highly positively related to peer-rated performance (Demerouti et al., 2014). Moreover, self-rated performance has a unique advantage in our study because supervisors' ratings may be influenced by impression management behaviors (De Cuyper et al., 2014). Future studies could use multisource data, including self-rating scales, evaluations provided by employees' supervisors, and objective performance indexes, to further test the proposed model in the current study.

Third, future studies could explore the boundary condition of this two-pathway model. The current study found that both mediators existed between greed and job performance, and it is reasonable to speculate that some key contextual factors may influence which path plays a more important role. For instance, Knight and Mehta (2017) found a joint effect of social status and hierarchy stability on performance. Specifically, higher status individuals performed better than lower status individuals when hierarchy stability was high. This finding suggests that the effect of the need for social status may exist only when hierarchy stability is low, under which circumstance people with low status have more access to higher status.

Finally, the generalizability of the current results could be examined in different cultures. The cultural context of the current study, China, emphasizes social status much more than many other countries (Xi, 2016). Although the desire for status is fundamental and universal (Anderson et al., 2015), the importance people attach to it and the acceptable methods that people use to acquire it may vary among cultures. Huberman et al. (2004) compared the intrinsic value of status in the United States, Germany, Finland, Turkey, and China. They found that Chinese people pay more attention to social status and show more status-seeking behaviors than people from the other countries (Huberman et al., 2004). In addition, traditional Chinese values encourage people to improve their social status through their efforts and to pursue their wealth and status in moral ways (Xi, 2016). Future studies in different cultures are necessary to provide supporting evidence for the dual effect model of greed.

\section{DATA AVAILABILITY}

The datasets generated for this study are available on request to the corresponding author.

\section{ETHICS STATEMENT}

This study was carried out in accordance with the recommendations of the American Psychological Association Ethics Guidelines and the Committee on Human Protection and 
Ethics in Psychology. All subjects gave written informed consent in accordance with the Declaration of Helsinki. The protocol was approved by the Committee on Human Protection and Ethics in Psychology at Beijing Normal University.

\section{AUTHOR CONTRIBUTIONS}

YZ developed the study concept, and performed the data analysis and interpretation. $\mathrm{YZ}$ and $\mathrm{XS}$ created the study design and drafted the manuscript. SL performed the testing and data collection. GX provided the

\section{REFERENCES}

Adams, J. S. (1965). "Inequity in social exchange," in Advances in Experimental Social Psychology, ed. L. Berkowitz, (New York, NY: Academic Press), 267-299 doi: 10.1016/s0065-2601(08)60108-2

Akkermans, J., Paradniké, K., Van der Heijden, B. I. J. M., and De Vos, A. (2018). The best of both worlds: the role of career adaptability and career competencies in students' well-being and performance. Front. Psychol. 9:1678. doi: 10.3389/ fpsyg. 2018.01678

Alesina, A., Di Tella, R., and MacCulloch, R. (2004). Inequality and happiness: are europeans and americans different? J. Public Econ. 88, 2009-2042. doi: 10.1016/j.jpubeco.2003.07.006

Ambrose, M. L., Seabright, M. A., and Schminke, M. (2002). Sabotage in the workplace: the role of organizational injustice. Organ. Behav. Hum. Decis. Process. 89, 947-965. doi: 10.1037/a0012704

Anderson, C., Hildreth, J. A. D., and Howland, L. (2015). Is the desire for status a fundamental human motive? a review of the empirical literature. Psychol. Bull. 141, 574-601. doi: 10.1037/a0038781

Anderson, C., and Kilduff, G. J. (2009). Why do dominant personalities attain influence in face-to-face groups? the competence-signaling effects of trait dominance. J. Pers. Soc. Psychol. 96, 491-503. doi: 10.1037/a0014201

Balot, R. K. (2001). Greed and Injustice in Classic Athens. Princeton, NJ: Princeton University Press.

Belk, R. W. (1985). Materialism: trait aspects of living in the material world. J. Consumer Res. 12, 265-280.

Borman, W. C., and Motowidlo, S. J. (1997). Task performance and contextual performance: the meaning for personnel selection research. Hum. Perform. 10, 99-109. doi: 10.1207/s15327043hup1002_3

Brislin, R. W. (1970). Back-translation for cross-cultural research. J. Cross Cult. Psychol. 1, 185-216. doi: 10.1177/135910457000100301

Brown, P. H., Bulte, E., and Zhang, X. (2011). Positional spending and status seeking in rural China. J. Dev. Econ. 96, 139-149. doi: 10.1016/j.jdeveco.2010. 05.007

Bruhn, J. G., and Lowrey, J. (2012). The good and bad about greed: how the manifestations of greed can be used to improve organizational and individual behavior and performance. Consult. Psychol. J. Pract. Res. 64, 136-150. doi: $10.1037 / \mathrm{a} 0029355$

Byrne, B. M. (2012). Structural Equation Modeling With Mplus: Basic Concepts, Applications, and Programming. New York, NY: Routledge.

Campbell, W. K., Bonacci, A. M., Shelton, J., Exline, J. J., and Bushman, B. J. (2004). Psychological entitlement: Interpersonal consequences and validation of a self-report measure. J. Pers. Assess. 83, 29-45. doi: 10.1207/s15327752jpa 8301_04

Caudill, S. B. (1988). Practitioners corner: an advantage of the linear probability model over probit or logit. Oxf. Bull. Econ. Stat. 50, 425-427. doi: 10.1111/j. 1468-0084.1988.mp50004005.x

Cohen, T. R., Gunia, B. C., Kim-Jun, S. Y., and Murnighan, J. K. (2009). Do groups lie more than individuals? honesty and deception as a function of strategic self-interest. J. Exp. Soc. Psychol. 45, 1321-1324. doi: 10.1016/j.jesp.2009. 08.007 revisions. All authors approved the final version of the manuscript for submission.

\section{FUNDING}

This study was funded by the Fundamental Research Funds for the Central Universities, the State Scholarship Fund from the China Scholarship Council (Grant Number 201406045033), the National Natural Science Foundation of China (Grant Number 71971028), and the Advanced Innovation Center for Future Education at Beijing Normal University (Grant Number 27900-110631111).

Colquitt, J. A., Conlon, D. E., Wesson, M. J., Porter, C. O., and Ng, K. Y. (2001). Justice at the millennium: a meta-analytic review of 25 years of organizational justice research. J. Appl. Psychol. 86, 425-445. doi: 10.1037/0021-9010.86.3.425

Colquitt, J. A., Scott, B. A., Rodell, J. B., Long, D. M., Zapata, C. P., Conlon, D. E., et al. (2013). Justice at the millennium, a decade later: a meta-analytic test of social exchange and affect-based perspectives. J. Appl. Psychol. 98, 199-236. doi: $10.1037 / \mathrm{a} 0031757$

De Clercq, D., Haq, I. U., and Azeem, M. U. (2018). The roles of informational unfairness and political climate in the relationship between dispositional envy and job performance in pakistani organizations. J. Business Res. 82, 117-126. doi: 10.1016/j.jbusres.2017.09.006

De Cuyper, N., Schreurs, B., Vander Elst, T., Baillien, E., and De Witte, H. (2014). Exemplification and perceived job insecurity. J. Pers. Psychol. 13, 1-10.

Demerouti, E., Xanthopoulou, D., Tsaousis, I., and Bakker, A. B. (2014). Disentangling task and contextual performance. J. Pers. Psychol. 13, 59-69. doi: 10.1027/1866-5888/a000104

Ezard, J. (2000). SEVEN Out of 10 Office Staff Prefer Grander Job Title to Pay Rise. Available at: http://www.theguardian.com/money/2000/apr/18/ workandcareers.pay (accessed June 23, 2018).

Flynn, F. J., Reagans, R. E., Amanatullah, E. T., and Ames, D. R. (2006). Helping one's way to the top: self-monitors achieve status by helping others and knowing who helps whom. J. Pers. Soc. Psychol. 91, 1123-1137. doi: 10.1037/0022-3514. 91.6.1123

Flynn, L. R., Goldsmith, R. E., and Pollitte, W. (2016). Materialism, status consumption, and market involved consumers. Psychol. Market. 33, 761-776. doi: 10.1002/mar.20915

Fornell, C., and Larcker, D. F. (1981). Evaluating structural equation models with unobservable variables and measurement error. J. Market. Res. 18, 39-50. doi: $10.1177 / 002224378101800104$

Gilliland, S. W., and Anderson, J. (2011). "Perceptions of greed: A distributive justice model," in Emerging Perspectives on Organizational Justice and Ethics, eds S. W. Gilliland, D. D. Steiner, and D. P. Skarlicki, (Charlotte, NC: Information Age Publishing), 137-166.

Greenberg, J. (2002). Who stole the money, and when? Individual and situational determinants of employee theft. Organ. Behav. Hum. Decis. Process. 89, 9851003. doi: 10.1016/s0749-5978(02)00039-0

Greenberg, J. (2004). Stress fairness to fare no stress: managing workplace stress by promoting organizational justice. Organ. Dyn. 33, 352-365. doi: 10.1016/j. orgdyn.2004.09.003

Greenfeld, L. (2003). The spirit of capitalism: Nationalism and economic growth. Cambridge, Massachusetts and. London: Harvard University Press.

Hardy, C. L., and Van Vugt, M. (2006). Nice guys finish first: the competitive altruism hypothesis. Pers. Soc. Psychol. Bull. 32, 1402-1413. doi: 10.1177/ 0146167206291006

Highhouse, S., Brooks, M. E., and Wang, Y. (2016). Status Seeking and Manipulative Self-presentation. Int. J. Sel. Assess. 24, 352-361. doi: 10.1111/ ijsa. 12153

Huberman, B. A., Loch, C. H., and Önçüler, A. (2004). Status as a valued resource. Soc. Psychol. Q. 67, 103-114. doi: 10.1177/019027250406700109

Hume, D. (2001). A Treatise of Human Nature. Oxford: Oxford University Press. 
Huseman, R. C., Hatfield, J. D., and Miles, E. W. (1987). A new perspective on equity theory: the equity sensitivity construct. Acad. Manag. Rev. 12, 222-234. doi: 10.5465/amr.1987.4307799

Kickul, J., and Lester, S. W. (2001). Broken promises: equity sensitivity as a moderator between psychological contract breach and employee attitudes and behavior. J. Business Psychol. 16, 191-217.

Kilduff, G. J., Willer, R., and Anderson, C. (2016). Hierarchy and its discontents: status disagreement leads to withdrawal of contribution and lower group performance. Organ. Sci. 27, 373-390. doi: 10.1287/orsc.2016. 1058

Knight, E. L., and Mehta, P. H. (2017). Hierarchy stability moderates the effect of status on stress and performance in humans. Proc. Nat. Acad. Sci. U.S.A. 114, 78-83. doi: 10.1073/pnas.1609811114

Krekels, G., and Pandelaere, M. (2015). Dispositional greed. Pers. Ind. Dif. 74, 225-230. doi: 10.1016/j.paid.2014.10.036

Krekels, G., Pandelaere, M., and Weijters, B. (2011). Dispositional greed: scale development and validation. Adv. Consum. Res. 39, 799-800.

Leventhal, G. S. (1976). "What should be done with equity theory? New approaches to the study of fairness in social relationships," in Social Exchange: Advances in Theory and Research, eds K. Gergen, M. Greenberg, and R. Willis, (New York, NY: Plenum), 27-55. doi: 10.1007/978-1-4613-3087-5_2

Levine, R. (2005). Finance and growth: theory and evidence. Handbook Econ. Growth 1, 865-934. doi: 10.1016/s1574-0684(05)01012-9

Liu, Z., Sun, X., Ding, X., Hu, X., Xu, Z., and Fu, Z. (2019). Psychometric properties of the Chinese version of the Dispositional Greed Scale and a portrait of greedy people. Pers. Ind. Dif. 137, 101-109. doi: 10.1016/j.paid.2018. 08.012

Magee, J. C., and Galinsky, A. D. (2008). 8 Social Hierarchy: the self-reinforcing nature of power and status. Acad. Manag. Ann. 2, 351-398. doi: 10.5465/ 19416520802211628

Motowidlo, S. J., and Van Scotter, J. R. (1994). Evidence that task performance should be distinguished from contextual performance. J. Appl. Psychol. 79, 475-480. doi: 10.1037/emo0000166

Mussel, P., Reiter, A. M., Osinsky, R., and Hewig, J. (2015). State-and trait-greed, its impact on risky decision-making and underlying neural mechanisms. Soc. Neurosci. 10, 126-134. doi: 10.1080/17470919.2014.965340

Niehoff, B. P., and Moorman, R. H. (1993). Justice as a mediator of the relationship between methods of monitoring and organizational citizenship behavior. Acad. Manag. J. 36, 527-556. doi: 10.5465/256591

Oka, R., and Kuijt, I. (2014). Introducing an inquiry into the social economies of greed and excess. Econ. Anthropol. 1, 1-16.

Podsakoff, P. M., MacKenzie, S. B., Lee, J. Y., and Podsakoff, N. P. (2003). Common method biases in behavioral research: a critical review of the literature and recommended remedies. J. Appl. Psychol. 88:879. doi: 10.1037/0021-9010.88. 5.879

Rose-Ackerman, S. (1999). Political corruption and democracy. Conn. J. Int. Law $14,363-378$.

Seuntjens, T. G., Zeelenberg, M., van de Ven, N., and Breugelmans, S. M. (2015). Dispositional greed. J. Pers. Soc. Psychol. 108, 917-933. doi: 10.1037/ pspp0000031

Seuntjens, T. G., Zeelenberg, M., van de Ven, N., and Breugelmans, S. M. (2019). Greedy bastards: testing the relationship between wanting more and unethical behavior. Pers. Ind. Dif. 138, 147-156. doi: 10.1016/j.paid.2018.09.027

Smith, R. G. (2003). Serious Fraud in Australia and New Zealand. Canberra: Australian Institute of Criminology.

Tripp, T. M., Bies, R. J., and Aquino, K. (2002). Poetic justice or petty jealousy? The aesthetics of revenge. Organ. Behav. Hum. Decis. Process. 89, 966-984. doi: 10.1016/s0749-5978(02)00038-9

Van Dyne, L., and LePine, J. A. (1998). Helping and voice extra-role behaviors: Evidence of construct and predictive validity. Acad. Manag. J. 41, 108-119. doi: $10.2307 / 256902$

Veselka, L., Giammarco, E. A., and Vernon, P. A. (2014). The Dark Triad and the seven deadly sins. Pers. Ind. Dif. 67, 75-80. doi: 10.1016/j.paid.2014.01.055

Wang, L., Malhotra, D., and Murnighan, J. K. (2011). Economics education and greed. Acad. Manag. Learn. Educ. 10, 643-660. doi: 10.5465/amle.2009.0185

Wang, X. (2009). An Empirical Study on the Structure and Reality of Organizational Justice in China. Manag. Rev. 21, 39-47.

Wang, X., and Liao, J. (2009). The Impact of Organizational Justice on Work Performance: the Mediating effects of Organizational Commitment and Leadermember Exchange. Ind. Eng. Manag. 14, 97-102.

Willer, R. (2009). Groups reward individual sacrifice: the status solution to the collective action problem. Am. Sociol. Rev. 74, 23-43. doi: 10.1177/ 000312240907400102

Xi, C. (2016). status concern and relative deprivation in china: measures, empirical evidence and economic and policy implications. China 14, 151-170.

Conflict of Interest Statement: The authors declare that the research was conducted in the absence of any commercial or financial relationships that could be construed as a potential conflict of interest.

Copyright (c) $2019 \mathrm{Zhu}$, Sun, Liu and Xue. This is an open-access article distributed under the terms of the Creative Commons Attribution License (CC BY). The use, distribution or reproduction in other forums is permitted, provided the original author(s) and the copyright owner(s) are credited and that the original publication in this journal is cited, in accordance with accepted academic practice. No use, distribution or reproduction is permitted which does not comply with these terms. 